\title{
Stomatal Lineage Control by Developmental Program and Environmental Cues
}

\author{
Soon-Ki Han ${ }^{1 *}$, June M. Kwak ${ }^{1}$ and Xingyun $\mathrm{Qi}^{2 *}$ \\ ${ }^{1}$ Department of New Biology, DGIST, Daegu, South Korea, ${ }^{2}$ Department of Biology, Rutgers University, Camden, NJ, \\ United States
}

Stomata are micropores that allow plants to breathe and play a critical role in photosynthesis and nutrient uptake by regulating gas exchange and transpiration. Stomatal development, therefore, is optimized for survival and growth of the plant despite variable environmental conditions. Signaling cascades and transcriptional networks that determine the birth, proliferation, and differentiation of a stomate have been identified. These networks ensure proper stomatal patterning, density, and polarity. Environmental cues also influence stomatal development. In this review, we highlight recent findings regarding the developmental program governing cell fate and dynamics of stomatal lineage cells at the cell state- or single-cell level. We also overview the control of stomatal development by environmental cues as well as developmental plasticity associated with stomatal function

Edited by:

Wenxiu Ye,

Shanghai Jiao Tong University, China

Reviewed by:

Jin Suk Lee,

Concordia University, Canada Eigo Ando,

The University of Tokyo, Japan

${ }^{*}$ Correspondence:

Soon-Ki Han

soonhan@dgist.ac.kr Xingyun Qi

xq67@camden.rutgers.edu

Specialty section: This article was submitted to Plant Cell Biology, a section of the journal

Frontiers in Plant Science

Received: 02 August 2021 Accepted: 10 September 2021

Published: 11 October 2021

Citation:

Han S-K, Kwak JM and Qi X (2021) Stomatal Lineage Control by Developmental Program and Environmental Cues.

Front. Plant Sci. 12:751852. doi: 10.3389/fp/s.2021.751852 and physiology. Recent advances in our understanding of stomatal development will provide a route to improving photosynthesis and water-stress resilience of crop plants in the climate change we currently face.

Keywords: stomatal lineage, development, transcription, environment

\section{INTRODUCTION}

When plants transition from water to land, they became more exposed to carbon dioxide $\left(\mathrm{CO}_{2}\right)$ and arid conditions. The evolution of stomata enabled plants to respond to the increased $\mathrm{CO}_{2}$ availability and limit water loss, ensuring their survival on land. Stomata are micropores on plant surface that are surrounded by two guard cells. These stomata open and close to facilitate gas exchange between plant inner tissues and the environment. Optimal gas exchange and water usage require efficient allocation of leaf surface to stomata. Improper stomatal patterning and density result in a change in mesophyll tissues and the epidermal area, affecting photosynthesis (Chen et al., 2016). Stomatal development, therefore, is tightly regulated to ensure there is no loss in photosynthesis efficiency.

Stomata are found in most land plants (Duckett and Pressel, 2018), and the basic morphology is highly conserved (Chen et al., 2017). Most land plants, including Arabidopsis and grasses, undergo stomatal lineage progression and bear similar molecular components despite their substantial differences in morphology and arrangements (Raissig et al., 2016; Hepworth et al., 2018; Conklin et al., 2019; McKown and Bergmann, 2020). In dicotyledonous Arabidopsis, stomatal development initiates from a subset of protodermal cells, meristemoid mother cells (MMCs), which gain stem-cell fate (Figure 1). These MMCs undergo several rounds of amplifying division, where asymmetric division occurs in an inward spiral manner. Each round of asymmetric 


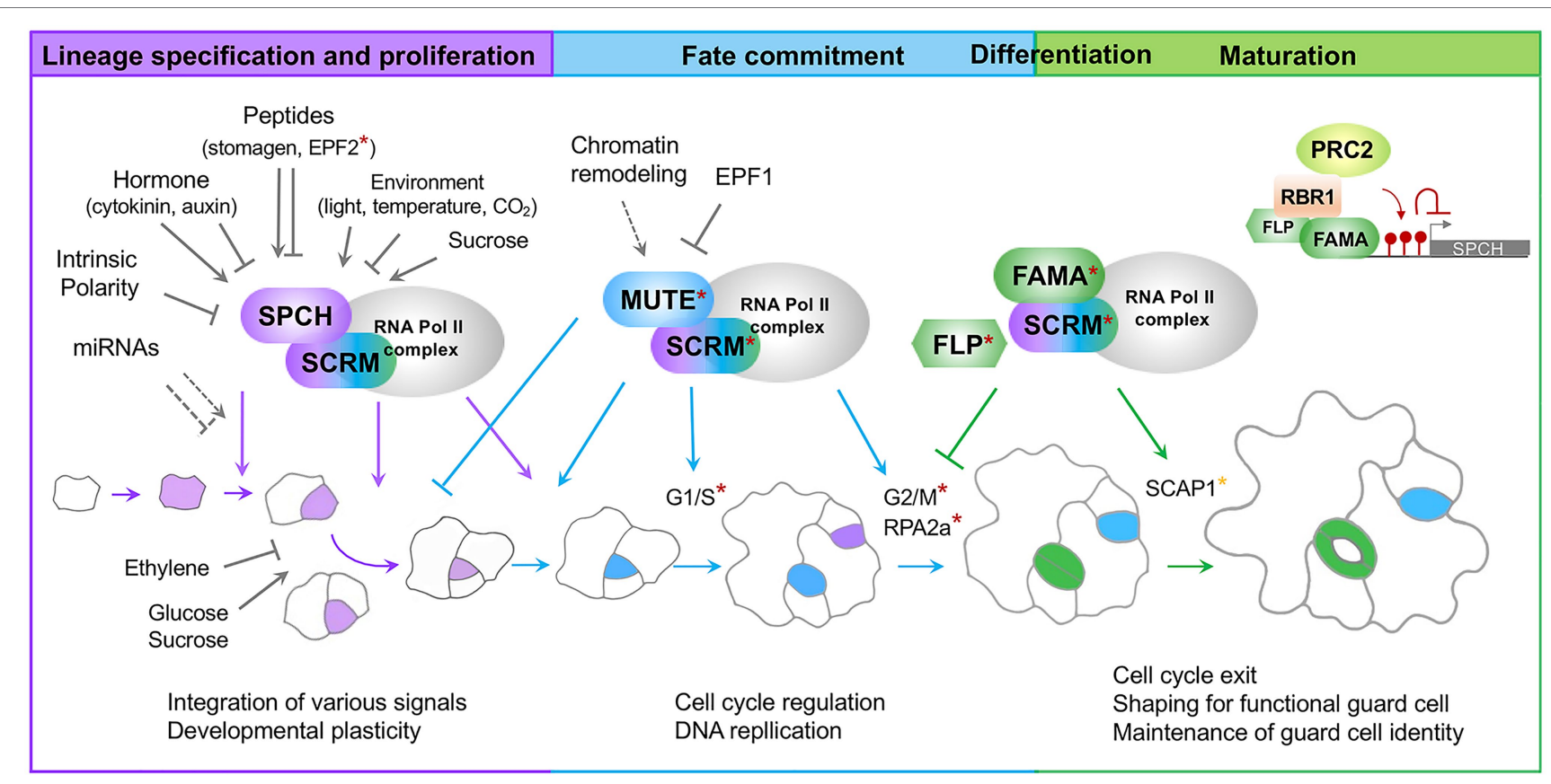

FIGURE 1 | A current model for Stomatal development in Arabidopsis. Stomatal lineage progression is mediated by a sequential action of the developmental stage-specific transcription factors. SPCH/SCRM are responsible for lineage specification and proliferation; MUTE/SCRM for fate commitment; FAMA/SCRM for differentiation and maturation. Developmental and environmental signals primarily modulate the first step mediated by SPCH/SCRM. A subunit of the RNA polymerase II complex and associated proteins interact with core transcription factors. Direct targets for MUTE and FAMA are denoted by asterisks in red and orange, respectively. Cells highlighted in purple indicate stomatal lineage precursors. Cells highlighted in blue are late meristemoids and GMCs. Cells highlighted in green are immature and mature guard cells. Colored arrows indicate positive regulation of transcription factors. Colored, inverted Ts indicate negative regulation of transcription factors. Arrows and closed lines in gray indicate developmental and environmental factors regulating transcription factors or stomatal lineage cells. A dotted line indicates potential regulation. SPCH, SPEECHLESS; SCRM, ICE1/SCRM2; FLP, FOUR LIPS; RPA2A, a core subunit of Replication Protein A complexes; SCAP1, STOMATAL CARPENTER 1; RBR1, RETINOBLASTOMA-RELATED 1; PRC2, Polycomb Repressive Complex 2; EPF, Epidermal Patterning Factor; G1/S G2M, phases of cell cycle.

division yields a small daughter cell, a meristemoid, and a large daughter cell, a stomatal lineage ground cell (SLGC). Meristemoids become guard mother cells (GMCs) which further undergo a single round of symmetric division and differentiation. This process produces two mirror-symmetric guard cells with a pore in the center. SLGCs can continue with spacing division, in which they divide asymmetrically to generate satellite stomata, or they can differentiate into pavement cells (Han and Torii, 2016; Lee and Bergmann, 2019). The stomatal complexes of monocotyledonous grass species are distinct from those in eudicot. Dumbbell-shaped guard cells are accompanied by subsidiary cells, arranged in parallel to the leaf vein, and develop without stem cell-like meristemoid cells. The initiation of stomatal lineage by an asymmetric division of the precursor cells directly produces GMCs. The neighboring cells of the newly formed GMCs acquire subsidiary mother cell (SMC) fate and establish polarity toward the adjacent GMC. After the SMCs asymmetrically divide and differentiate into subsidiary cells, the GMCs divide symmetrically to generate a pair of guard cells. Two guard cells and subsidiary cells together form a dumbbell-shaped stomatal complex (Hepworth et al., 2018; Nunes et al., 2020).

Stomatal development is sequentially controlled by three basic helix-loop-helix (bHLH) transcription factors,
SPEECHLESS (SPCH), MUTE, and FAMA. These transcription factors work together with their heterodimeric partners SCRM (ICE1) and SCRM2 (Ohashi-Ito and Bergmann, 2006; MacAlister et al., 2007; Pillitteri et al., 2007; Kanaoka et al., 2008; Figure 1). The SPCH/SCRM heterodimer determines stomatal fate and maintains the proliferation step by promoting asymmetric division (MacAlister et al., 2007). The MUTE/SCRM dimer terminates the proliferative state initiated by SPCH/SCRM and drives differentiation of meristemoids to GMCs (Pillitteri et al., 2007). The FAMA/SCRM dimer induces guard cell differentiation and restricts the last symmetric division to form a pair of guard cells (Ohashi-Ito and Bergmann, 2006). Two closely related R2R3 MYB transcription factor genes, FOUR LIPS (FLP) and $M Y B 88$, function in a semi-redundant manner with FAMA in differentiation and coordination of the terminal symmetric cell division (Geisler et al., 1998).

bHLH genes regulating stomatal development are well conserved across the land plants (Liu et al., 2009). However, their function is alternatively wired among different species to accommodate the fundamental difference in the patterning and shape of stomatal complexes. In particular, two copies of $S P C H$ that function redundantly at the entry of stomatal lineage are found in Brachypodium and rice (Raissig et al., 2016). In contrast to Arabidopsis, MUTE protein in grass species can 
move from GMCs to the adjacent cells (Raissig et al., 2017; Wang et al., 2019; Wu et al., 2019). This lateral movement of MUTE establishes the identity of SMCs and drives the differentiation of subsidiary cells in a non-cell-autonomous fashion (Nunes et al., 2020).

Expression profiling of stomatal lineage cells at different developmental stages has revealed dynamic changes in the transcriptomes (Pillitteri et al., 2011; Adrian et al., 2015; Zhu et al., 2020; Ho et al., 2021). Moreover, direct target genes of the three master transcription factors have been identified (Hachez et al., 2011; Lau et al., 2014; Han et al., 2018). The recent advance in single-cell RNA-sequencing technology enables profiling spatiotemporal gene expression at the level of the individual stomatal lineage cells (Liu et al., 2020; Lopez-Anido et al., 2021). The systems-level analyses of stomatal lineage cells have deepened our understanding of how the developmental stage-specific transcriptional factors fulfill the developmental program.

Mitogen-Activated Protein Kinase (MAPK) cascades consist of YODA (YDA), MKK4/5/7/9, and MPK3/6. These cascades act upstream of the developmental stage-specific transcription factors (Bergmann et al., 2004; Wang et al., 2007). The activation of the MAPK cascade destabilizes SPCH and MUTE (Lampard et al., 2008; Qi et al., 2017). YDA-MPK3/6 MAPK signaling also plays a substantial role in establishing the cellular polarity required for asymmetric division and stomatal fate specification (Zhang et al., 2015, 2016). The molecular switch that either activates or suppresses the MAPK cascade, at least in part, consists of secreted epidermal patterning factor (EPF) peptides. EPF peptides are perceived by their corresponding cell-surface receptor complexes composed of the proteins belonging to the ERECTA family and their co-receptors TMM and SERK families (Torii, 2012). EPFs and their cognate receptors are conserved throughout the land plants (Caine et al., 2016; Hepworth et al., 2018). Functional studies of monocot species suggest that EPF1 and EPF2 inhibit, but EPFL9 enhances stomatal development, indicating that they are the functional ortholog of Arabidopsis EPFs (Franks et al., 2015; Hepworth et al., 2015; Wang et al., 2016; Hughes et al., 2017; Caine et al., 2019; Dunn et al., 2019; Mohammed et al., 2019). In addition, PANGLOSS1 and PANGLOSS 2 are Leucine-Rich-Repeat receptors in grasses and promote polarization of asymmetric SMC division (Cartwright et al., 2009; Facette and Smith, 2012; Facette et al., 2015). This result implies divergent receptor complexes perceive the extrinsic signal to modulate stomatal development.

Stomatal development is tightly controlled to ensure growth and survival and allows the plant to adapt to environmental changes. The current global climate changes could directly affect stomatal development and function and, thus, plant growth. $\mathrm{CO}_{2}$ is a gas that exacerbates the greenhouse effect and, therefore, global climate change (Lindsey, 2020). Temperature increases are often accompanied by drought stress due to enhanced water evaporation and changing rain patterns. Both excessive heat and drought stress negatively impact plant production. A significant loss $(80-90 \%)$ in grain yield can result from warm temperatures during the plant reproductive stage (Hatfield and Prueger, 2015). Given the role of stomata in plant growth, further investigation of stomatal development and their response to environmental changes would provide a strategy that could enhance plant performance and productivity despite global climate change (Dow and Bergmann, 2014; Buckley et al., 2019).

\section{TRANSCRIPTIONAL CONTROL OF STOMATA DEVELOPMENT}

\section{Initiation and Maintenance of Stomatal Lineage Stem Cells}

Stomatal lineage specification initiates with the $S P C H$ expression in a subset of protodermal cells. This expression defines MMCs and continues through several rounds of asymmetric division. Persistent SPCH activity is found in meristemoids. The molecular signature of meristemoids was found via transcriptome analysis of stomatal development mutants overwhelmingly composed of meristemoids (Pillitteri et al., 2011). Pillitteri et al. identified the polarity protein POLAR and found that the cytokinin signaling pathway involving ARRs and CLEs, and ERECTAfamily receptor-like kinases were part of the molecular feature of stem-cell populations.

How SPCH contributes to the specification and proliferation of stomatal lineage cells has been uncovered by identifying the targets of SPCH. Genome-wide profiling of SPCH targets was conducted by analyzing the transcriptome of transgenic plants harboring SPCH under the control of an inducible promoter and chromatin immunoprecipitation sequencing (Lau et al., 2014). The key regulatory genes, including SCRMs, TMM, ERL2, EPF2, BASL, POLAR, and the ARK3/AtKINUa kinesins, and brassinosteroid biosynthetic and response genes were found to be regulated by SPCH. The other genes identified as $\mathrm{SPCH}$ targets include PHYTOCHROME-INTERACTING FACTOR 4 (PIF4; Lau et al., 2018), CLE9/10, and ARR16/17 (Vaten et al., 2018). These genes highlight the role of SPCH as an integrator conferring developmental flexibility of stomatal lineage in response to environmental or hormonal stimuli.

\section{New Players and Refining the Paradigm}

A recent study using single-cell transcriptome analysis of stomatal lineage cells has proposed an extended role for $\mathrm{SPCH}$ in reinforcing cell fate decisions (Lopez-Anido et al., 2021). SPCH appears to be expressed beyond the early stages of stomatal development and co-expressed with either MUTE or FAMA. This observation was supported by a reporter gene analysis showing the SPCH expression in GMCs and a small population of young guard cells. These findings contradict the existing paradigm that stomatal development proceeds with the sequential actions of the master transcription factors in each state of transition. Furthermore, the coding sequence of $S P C H$ did not fully complement the spch null mutants due to the disrupted level and timing of SPCH expression. This lack of complement resulted in a reduced number of stomata and defects in fate commitment to GMCs. Similar defects were observed in knockdown mutants for SPCH by artificial microRNAs (miRNAs) 
expressed under the MUTE promoter. Time-lapse imaging visualizing SPCH and MUTE protein expression showed overlapping expression patterns in late meristemoids (Davies and Bergmann, 2014). These studies indicate that SPCH activity is required for proper conversion of meristemoids to GMCs. It remains elusive, however, how SPCH functions in the later stages of stomatal development.

Another scRNA-seq analysis of stomatal lineage cells identified 11 cell clusters of epidermal cells, including two cell types that cannot be classified with known marker genes (Liu et al., 2020). One of the unclassified epidermal cell types highly expresses transcription factors and displays relatively similar patterns to early meristemoids in the developmental trajectory, suggesting that variable cell populations may exist at early stomatal developmental stages. This study also suggests potential regulators of stomatal development and a possible genetic network: BASIC PENTACYSTEINE (BPC) gene family and WRKY33 genes are highly expressed in the MMC through GMC state. Higher-order BPC mutants exhibit defects in stomatal patterning and arrested precursors. Although SPCH was unaffected by the $b p c$ sextuple mutants, the expression levels of SCRMs, MUTE, and FAMA were reduced. The detailed mechanism related to these transcription factors in stomatal development requires further investigation. Because the plantspecific BPCs family is involved in the recruitment of repressive histone-modifying complexes (Hecker et al., 2015; Mu et al., 2017; Xiao et al., 2017), it would be intriguing to test whether dynamic chromatin changes occur through the action of the BPC family during stomatal lineage progression.

\section{MUTE, a Potent Inducer of Cell Cycle Regulators for Stomata}

MUTE terminates the self-renewing meristemoid state initiated by SPCH. It triggers unidirectional differentiation accompanied by a single symmetric division to create a stomate surrounded by a pair of guard cells (Pillitteri et al., 2007). Genome-wide transcriptome analysis of transgenic plants in which MUTE is chemically induced (iMUTE) revealed a comprehensive MUTE-dependent gene expression profile (Han et al., 2018). MUTE shares the targets of stomatal genes with SPCH for continued lineage progression. MUTE directly induces SCRMs, ERL1, POLAR, and BASL-like SPCH. In contrast, the earlier EPF2 signal induced by SPCH is attenuated by MUTE activation. The expression of the common receptors (ERLs), however, is maintained to receive the EPF1 signal. These findings suggest that MUTE serves as a transcriptional switch for proper stomatal patterning. The majority of GO categories of genes up-regulated in the iMUTE plants include cell cycle and cell division, which is unique to the $i M U T E$ transcriptome compared to that of iSPCH. MUTE directly induces expression of cell cycle activators, CDKs and cyclins, followed by the activation of cell cycle repressors, FAMA and FLP, which in turn ensures symmetric division occurs only once (Han et al., 2018).

The scRNA-seq analysis further defines the molecular signature of fate commitment at single-cell resolution by showing how cell state-specific transcription factors, chromatin remodelers, and cell cycle regulators are dynamically regulated (LopezAnido et al., 2021). After the onset of fate commitment is triggered by MUTE, phase transition of the cell cycle is observed in discrete clusters. There, MUTE (G1/S of the cell cycle) and FAMA (G2/M of the cell cycle) are exclusively expressed.

The R2R3-MYB transcription factor FLP functions redundantly with FAMA for stomatal differentiation and direct repression of the cell cycle genes (Xie et al., 2010; Lee et al., 2014b). Enhanced terminal symmetric division in a loss-of-function mutant of FLP exhibits paired stomata. Yang et al. have shown that the paired stomata phenotype of $f p$ mutants can be suppressed by introducing the rpa2a mutation. The RPA2a subunit of the Replication Protein A (RPA) complexes is responsible for DNA replication, recombination, and repair, functions cooperatively with CDKB1s and CYCA2s in restricting terminal symmetric division and in maintaining DNA content and guard cell size. Therefore, phenotypic suppression of the flp mutant by rpa2a mutation is likely due to the failure of cell cycle checkpoints without RAP2a (Yang et al., 2019). Triggered by CDKB1s, RPA2a phosphorylation is associated with nuclear localization and function in DNA replication processes. It appears that the expression of RPA2a and genes involved in DNA replication is increased in the iMUTE plants (Han et al., 2018).

These findings indicate that during stomatal formation, MUTE contributes to timely coordination of the cell cycle. Further investigation is required to unveil how the cell cycle and the chromatin landscape are linked to the termination of a self-renewing state and fate commitment.

\section{Fate Decision of Stomatal Lineage Ground Cells}

SLGCs are large daughter cells derived from asymmetric divisions of MMCs or meristemoids. SLGCs bear bi-potency, meaning that they can either reenter asymmetric division to generate a satellite stomate or they can differentiate into a pavement cell.

Previously, it was shown that prolonged MUTE expression in 2-week-old mute mutants, where the meristemoids and SLGCs are arrested after several rounds of asymmetric division, resulted in clustered stomata (Trivino et al., 2013). In contrast, induced MUTE expression in wild-type plants did not show the clustered stomata phenotype due to full differentiation of stomatal lineage cells (Trivino et al., 2013). This result implies that SLGCs adjacent to the arrested meristemoid are competent to be a stomate. Additionally, it shows that SLGC differentiation to a pavement cell may require the MUTE activity in meristemoids.

Some molecular features of SLGCs were obtained from the transcriptome analyses of early stomatal lineage cells. It appears that SLGCs are enriched with genes associated with cell division and cytokinesis; they are poised between proliferation and endoreduplication-coupled differentiation (Ho et al., 2021). Fate decision to pavement cells or termination of proliferative SLGCs might also be linked to auxin-mediated onset of endoreduplication (John and Qi, 2008). It was reported that an auxin response gradient is formed and fluctuates within SLGCs, which helps to determine the fate and morphology of pavement cells 
(Grones et al., 2020). Cytokinin signaling, however, preferentially promotes asymmetric divisions in SLGCs (spacing division) through the induction of SPCH expression. SPCH directly regulates genes encoding the cytokinin inhibitory effector ARR16 and the secreted peptide CLE9. ARR16 reduces the cytokinin sensitivity of SLGCs, and CLE9 suppresses SLGC division. A negative feedback regulatory circuit, therefore, is formed between cytokinin and SPCH to fine-tune SLGC divisions (Vaten et al., 2018).

Despite the recent findings, the mechanism allowing SLGCs to maintain proliferate-state or to differentiate remains unknown. Although it is challenging to define the characteristics of SLGCs due to their heterogeneity, asynchronous production, and lack of specific SLGC markers, a detailed molecular characterization of SLGCs should enhance the investigation.

\section{Shaping Guard Cells and Maintenance of Guard Cell Fate}

The final step of consecutive state transition in stomatal development is mediated by the transcription factor FAMA. It promotes guard cell differentiation and negatively controls symmetric division of GMCs (Ohashi-Ito and Bergmann., 2006). FAMA appears to be directly induced by MUTE. However, unlike other MUTE targets induced immediately, FAMA induction is delayed until just prior to symmetric division (Han et al., 2018). This delay implies there is an additional mechanism regulating FAMA expression. Hachez et al (Hachez et al., 2011) identified FAMA targets and regulators of guard cell development by transcript profiling of genes that are differentially modulated over chemically induced FAMA ( $i F A M A)$. These genes, regulated by FAMA, encode proteins with diverse functions, including transcription factors, cell cycle controllers, receptors, signaling proteins, and proteins associated with cell wall modification and metabolic processes (Hachez et al., 2011). This study supports the function of FAMA in differentiation of GMCs to guard cells and the maintenance of guard cell identity.

The loss-of-function mutant stomatal carpenter 1 (scap1) develops skewed and dysfunctional guard cells. SCAP1 encodes a Dof-type transcription factor and regulates the expression of key molecules in stomatal function and structure such as GORK (outward $\mathrm{K}^{+}$channel), MYB60, and PME6 (pectin methyltransferase; Negi et al., 2013). As a consequence, scap1 mutants display impaired ion homeostasis and esterification of extracellular pectins responsible for cell wall maturation lining the pores (Negi et al., 2013). The loss-of-function mutant for PME6 displays dysfunctional guard cell dynamics due to the mechanical change in the guard cells (Amsbury et al., 2016). The expression of FAMA and SCAP1 in guard cells and the rapid up-regulation of SCAP1 upon FAMA induction (iFAMA; Ohashi-Ito and Bergmann, 2006; Hachez et al., 2011; Negi et al., 2013) suggest that SCAP1 is a potential target of FAMA. Despite the role of SCAP1 during stomata maturation, the expression of SCAP1 is observed in young leaf primordia. Loss-of-function mutants display a reduced stomatal density and patterning defects (Castorina et al., 2016). The change in stomatal density and increased patterning defects suggests that SCAP1 plays an additional role in stomatal development.

A component of the RNA polymerase II complex plays a role in stomatal differentiation in concert with FAMA (Chen et al., 2016). The hypomorphic mutant for NRPB3, the third largest subunit of the RNA polymerase II complex, produces more stomatal lineage-, paired-, and non-stomatal cells. Interestingly, the $n r p b 3$ mutant synergistically produces a tumorlike structure when combined with fama and $f p$. NRPB3 physically interacts with FAMA and SCRM, but not with SPCH and MUTE. RPAP2 IYO MATE (RIMA) is another protein interacting with NRPB3. RIMA also physically interacts with SPCH, MUTE, FAMA, and SCRM (Chen et al., 2021). It appears that the state-specific transcription factors associated with the general transcription machinery give rise to the cell state-specific regulation of gene expression. Stomatal lineage cell divisions are thereby limited at later stages of stomatal development.

Guard cells are the terminal state of stomatal cell lineage. Fully differentiated guard cells must irreversibly lose their proliferation ability to maintain cellular identity for stomatal function. Failure in maintenance reverts a guard cell to a stomatal lineage precursor, leading to a re-initiation of early stomatal lineage from a differentiated stomate. Previous studies have shown that the RETINOBLASTOMA RELATED (RBR)FAMA and RBR-FLP interactions play a critical role in freezing the guard cell identity upon completion of differentiation (Lee et al., 2014a,b; Matos et al., 2014). These interactions mediate the RBR-mediated recruitment of Polycomb Repressive Complex 2 (PRC2) and establish the repressive histone modification H3K27me3 of the stomatal lineage genes (Lee et al., 2014a,b; Matos et al., 2014). This mechanism is partly supported by an analysis of the single-cell type transcriptome and histone modification (H3K27me3 and H3K4me3) dynamics in normal guard cells compared to the guard cells in the reprogramming state (FAMA ${ }^{\mathrm{LGK}}$; Lee et al., 2019). When point mutations are introduced in the RBR binding motif ( $\mathrm{LxCxE}$ ) of FAMA (referred as $\left.\mathrm{FAMA}^{\mathrm{LGK}}\right)$, FAMA ${ }^{\mathrm{LGK}}$ is not capable of interacting with $\mathrm{RBR}$ and recruiting PRC2 (Matos et al., 2014). Modest changes in H3K27me3 peaks were observed between WT and FAMA ${ }^{\text {LGK }}$. In FAMA ${ }^{\mathrm{LGK}}$ cells, the SPCH locus loses the H3K27me3 modification and its expression is concomitantly increased. The level of H3K27me3 at the MUTE and FAMA loci and their expression level, however, remained unchanged in the FAMA ${ }^{\mathrm{LGK}}$ guard cells. This finding suggests that de-repression of $\mathrm{SPCH}$ may contribute to the re-initiation of the stomatal lineage in FAMA $^{\mathrm{LGK}}$ and that $\mathrm{H} 3 \mathrm{~K} 27 \mathrm{me} 3$ is required to prevent guard cell fate from reverting to the precursor state. However, the MUTE expression level in FAMA ${ }^{\mathrm{LGK}}$ is contradictory to the previous report where MUTE is highly up-regulated in 15-dayold cotyledons of FAMA ${ }^{\mathrm{LGK}}$ (Matos et al., 2014).

SPCH expression alone is not capable of forming stomata (Davies and Bergmann, 2014). Ectopic SPCH expression results in more asymmetric divisions (Han et al., 2018). These results imply that the stomate in the stomate phenotype may not be solely attributable to the de-repression of SPCH. Knockdown of the PRC2 activity in guard cells mimics the stomate 
in the stomate phenotype with a very low frequency compared to $\mathrm{FAMA}^{\mathrm{LGK}}$. This activity suggests a minor contribution of $\mathrm{H} 3 \mathrm{~K} 27 \mathrm{me} 3$ and the presence of other mechanisms to maintain guard cell integrity. Indeed, H3K27me3 marks are increased on the locus of WOUND-INDUCED DEDIFFERENTIATION 1 (WIND3) during guard cell reprogramming (FAMA ${ }^{\mathrm{LGK}}$ ), thereby resulting in transcriptional down-regulation of WIND3. The ectopic expression of WIND3 using the SPCH promoter enhances the FAMA ${ }^{\mathrm{LGK}}$ phenotype. These results imply that guard cell integrity is maintained by complex mechanisms in addition to the known $\mathrm{H} 3 \mathrm{~K} 27 \mathrm{me} 3$ reorganization at the loci of stomatal lineage genes.

Using the proximity labeling method that identifies spatial and temporal information in protein-protein interactions, the nuclear proteome of young guard cells and novel FAMAinteracting proteins were identified (Mair et al., 2019). The FAMA interactors include bHLH transcriptional factors SCRM, transcriptional co-activators that link transcriptional factors to RNA polymerase II, and histone acetyltransferases, which is consistent with the previous study showing a link between FAMA and RNA polymerase II (Chen et al., 2016). FAMA also interacts with the transcriptional co-repressor TOPLESSrelated proteins that recruit histone deacetylases to transcriptional factors and their linker protein that mediates the interaction between the co-repressor complex with transcription factors (Long et al., 2006). Among the highly abundant proteins in the nuclei of young guard cells, SHL (SHORT LIFE) binds to both $\mathrm{H} 3 \mathrm{~K} 27 \mathrm{me} 3$ and $\mathrm{H} 3 \mathrm{~K} 4 \mathrm{me}$. SHL functions as a histone reader to direct a particular transcriptional outcome. It might be involved in the establishment of repressive chromatins in concert with the co-repressors to lock the guard cell identity in their terminally differentiated state. Overall, FAMA could positively or negatively regulate target genes in concert with the co-activators and the co-repressors. This regulation is likely mediated through histone acetylation/deacetylation in response to developmental or hormonal signals.

\section{SIGNALING CASCADE CONVERGING TO TRANSCRIPTION FACTORS}

Plant survival dictates that the level of expression and the activity of the master transcription factors in each state of stomatal development must be tightly regulated. SPCH expression is modulated directly by upstream transcription factors. These factors are induced by light, drought, and heat (Klermund et al., 2016; Lau et al., 2018; Qi et al., 2019). SPCH activity is crucial to determine the fate of bi-potent stomatal lineage cells after asymmetric division and is substantially modulated by various kinases. MAPK signaling cascades inhibit the SPCH activity (Lampard et al., 2008; Gudesblat et al., 2012; Yang et al., 2015; Han et al., 2020). The mechanism by which the expression and activity MUTE and FAMA are regulated, in contrast, is not fully understood yet.

The signaling pathway upstream of the bHLH transcription factors is initiated by the EPF-family ligands, ERECTA-family receptor-like kinases, TMM as a co-receptor, and the downstream MAPK signaling cascade. The EPF ligands belong to the peptide family secreted to the apoplast (Herrmann and Torii, 2020). Structural and biochemical analysis revealed that heterodimerization between the ER-family receptors and TMM is required for EPF1 and EPF2 ligand perception, but was not required for EPFL4/5/6 (Lin et al., 2017), which indicates that ligand-based selectivity of receptor heterodimerization specifies the downstream biological process. ER receptor-TMM modules can also associate with the co-receptors BRI1-ASSOCIATED RECEPTOR KINASE/ SOMATIC EMBRYOGENESIS RECEPTOR KINASE (BAK/ SERK) to form a ternary receptor complex. This complex contributes to the stabilization of a specific ligand-receptor pair and hence, confers higher specificity in signaling (Meng and Yao, 2015).

EPF1 and EPF2 peptide ligands negatively regulate stomatal formation (Hara et al., 2007, 2009; Hunt and Gray, 2009). EPF2 restricts the initiation of stomatal formation by reducing the stability of SPCH (Bergmann et al., 2004; Pillitteri et al., 2011; Robinson et al., 2011). Exaggerated EPF2 signaling leads to a plant leaf epidermis composed of only pavement cells, similar to the spch mutants (Hara et al., 2007; Rowe and Bergmann, 2010; Rychel et al., 2010). EPF2 expression is directly regulated by SPCH and SCRM (Lau et al., 2014; Horst et al., 2015). It is repressed by MUTE activity when the stomatal fate is committed in GMCs. This regulation allows EPF1 to access the common receptor system (Han et al., 2018). Another EPF-family member, EPF1, inhibits stomatal formation by negatively regulating the stability of the MUTE protein (Hara et al., 2007; Lee et al., 2012, 2015; Lin et al., 2017; Qi et al., 2017, 2020). Enhanced EPF1 signaling causes the stomatal lineage to arrest at the meristemoid state, phenocopying the mute mutants. Unlike $E P F 2, E P F 1$ expression is not directly regulated by MUTE (Qi et al., 2017). The transcription factors regulating EPF1 expression are unknown.

EPF-like 9 (EPFL9), also known as STOMAGEN, promotes stomatal formation and is highly responsive to environmental cues (Kondo et al., 2010; Sugano et al., 2010). With a highly similar topology structure, STOMAGEN competes with EPF1 and EPF2 for the same receptor complex but does not activate the MAPK cascade (Ohki et al., 2011; Lee et al., 2015; Qi et al., 2017). An auxin-related transcription factor MONOPTEROS (MP) suppresses the expression of STOMAGEN. The light-inducible transcription factor ELONGATED HYPOCOTYL 5 (HY5) induces STOMATAGEN expression (Wang et al., 2021).

SCRM functions as a scaffold protein and associates with MPK3/6 and SPCH (Putarjunan et al., 2019). MPK3/6 first binds to the bipartite SCRM-KRAAM motifs of SCRM, which bridges with SPCH. Then, it triggers the subsequent phosphorylation of $\mathrm{SPCH}$, resulting in the degradation of SPCH-SCRM (Putarjunan et al., 2019). The KRAAM motif is distinct from the putative MAPK docking sites and is uniquely found in SCRMs and their orthologs. This distinction suggests a mechanism for MAPKs conferring substrate specificity in a developmental process. 
The localization of the MAPK cascade is unevenly distributed in MMC and in the two daughter cells derived from an asymmetric division. This distribution is facilitated by the intrinsic polarity protein, BASL. BASL arranges the tethering of YDA-MPK signaling components at its polarized crescent of the membrane, which results in elevated $\mathrm{SPCH}$ phosphorylation/destabilization to reduce the concentration of SPCH protein in SLGCs (Zhang et al., 2015, 2016). YDA-MAPK signaling must be restricted to allow high division potential in MMCs. This process is mediated by the polarized POLARBRASSINOSTEROID-INSENSITIVE2 (BIN2) module at the polarity crescent. Polarized BIN2 can inhibit YDA, leading to the attenuation of the YDA-MAPK signaling (Houbaert et al., 2018; Guo and Dong, 2019). The protein phosphatase BRI1 SUPPRESSPR 1 (BSU1)-LIKE 1 (BSL1) associates with the polarity complex and subsequently triggers the translocation of BIN2 from the polar crescent to the nucleus. It also activates YDA-MAPK signaling in SLGCs. BIN2 in the nucleus directly phosphorylates and destabilizes SPCH. This destabilization further restricts asymmetric division and leads to differentiation (Gudesblat et al., 2012; Guo et al., 2021a,b).

MAP KINASE PHOSPHATASE1 (MKP1) fine-tunes the MAPK signaling by inactivating the MAPK cascade at the early stage of stomatal development (Tamnanloo et al., 2018). The $m k p 1$ mutants undergo the asymmetric entry division but fail to differentiate, resembling the mute mutant phenotype. Genetic analysis puts MKP1 upstream of MPK3/6 and downstream of YDA. Additionally, MPK3/6 signaling is hyperactivated when MKP1 is absent, suggesting MKP1 deactivates MPK3/6. Interestingly, MKP1 expression fully rescues the $m k p 1$ mutant phenotype only when the MPK1 expression is driven by the $\mathrm{SPCH}$ promoter. This result suggests that MKP1 has a significant role in controlling guard cell fate commitment in early stomatal precursor cells.

Phosphorylation on the SPCH protein usually leads to its degradation. Yet, phosphorylation on Thr49, Thr50, Ser51, and Ser52 of the SPCH protein has been shown to stabilize SPCH (Han et al., 2020). The accumulation of KIN10, a catalytic subunit of the conserved energy sensor kinase SnRK1, can be induced by sucrose and promotes stomatal development. KIN10 is highly expressed in the nuclei of stomatal lineage cells where it phosphorylates and stabilizes SPCH to promote sucrose-induced stomatal formation (Han et al., 2020). Mutations in KIN10 result in decreased stomatal index, while overexpression of KIN10 results in a higher stomatal index. This finding partly explains the previously observed stomatal phenotype when plants are treated with high doses of sucrose (Akita et al., 2013).

Multiple kinases phosphorylate $\mathrm{SPCH}$, resulting in the destabilization of SPCH. Protein phosphatases that are responsible for dephosphorylating SPCH, however, have recently been discovered (Bian et al., 2020). The scaffolding A subunit of the PP2A heterotrimeric complex directly associates with $\mathrm{SPCH}$. Loss-of-function mutations in PP2A or inactivation by PP2A inhibitors results in reduced stomata formation and round pavement cells. This result suggests that PP2A promotes stomatal development by positively regulating SPCH stability. Furthermore, undifferentiated precursors after asymmetric divisions and round pavement cells in the $p p 2 a$ mutants increase the likelihood that PP2A may regulate other proteins such as MUTE or those involved in pavement cell differentiation.

\section{ENVIRONMENTAL CUES AND DEVELOPMENTAL PLASTICITY}

Given the essential role of stomata in photosynthesis and nutrient uptake, stomatal development is tightly controlled in response to a diverse range of environmental and phytohormonal signals (Qi and Torii, 2018). Plants have developed a highly coordinated regulatory mechanism that balances the need for photosynthesis and transpiration according to their specific environment (Hepworth et al., 2016). Atmospheric $\mathrm{CO}_{2}$ concentration, water availability, environmental temperature, light intensity, and nutrients all influence the endogenous program (Figure 2).

\section{Environmental Factors Affecting Stomata Development}

\section{Carbon Dioxide}

Atmospheric $\mathrm{CO}_{2}$ significantly influences stomatal formation and function. Evolutionary studies over geologic time scale as well as ecological studies imply that atmospheric $\mathrm{CO}_{2}$ levels are inversely correlated with stomatal density and impacts on stomatal function (McElwain and Steinthorsdottir, 2017). Global climate impact assessments for crops have shown that elevated atmospheric $\mathrm{CO}_{2}$ levels may be a preferable condition to mitigate yield losses due to climate changes. This preference is because low atmospheric $\mathrm{CO}_{2}$ concentration imposes a negative repression on photosynthetic productivity (Sage and Coleman, 2001). In bread wheat, drought stress often causes reduction in seed yield, but this loss can be compensated by an elevated $\mathrm{CO}_{2}$ level. This compensation is likely due to the high $\mathrm{CO}_{2}$ concentration satisfying the photosynthesis needs more efficiently when stomatal conductance is limited by water shortage (Dunn et al., 2019). $\mathrm{CO}_{2}$ enrichment often comes with other climate changes including rising temperatures and water shortages. The response of decreasing stomatal density at a high $\mathrm{CO}_{2}$ level, therefore, implies that the ease in $\mathrm{CO}_{2}$ uptake allows plants to respond to other limiting factors such as water availability.

The current understanding of how $\mathrm{CO}_{2}$ regulates stomatal formation comes from a milestone study by Schroeder and his colleagues (Engineer et al., 2014; Figure 2). They found that Arabidopsis $\beta$-carbonic anhydrase double mutants (calca4; $\mathrm{Hu}$ et al., 2010) display an increased stomata density at an elevated $\mathrm{CO}_{2}$ level. This increase in stomata density was due to compromised EPF2 expression. This study identified $\mathrm{CO}_{2}$ RESPONSE SECRETED PROTEASE (CRSP), which is induced by elevated $\mathrm{CO}_{2}$ level and encodes a protease that specifically cleaves the precursor of EPF2 to release the mature peptide into the apoplast. The processed, functional EPF2 inhibits stomatal initiation by destabilizing SPCH. Mutations in either CRSP or EPF2 impair the stomatal development influenced by elevated $\mathrm{CO}_{2}$ concentration (Engineer et al., 2014). Moreover, treatments with a high concentration of $\mathrm{CO}_{2}$ promote 


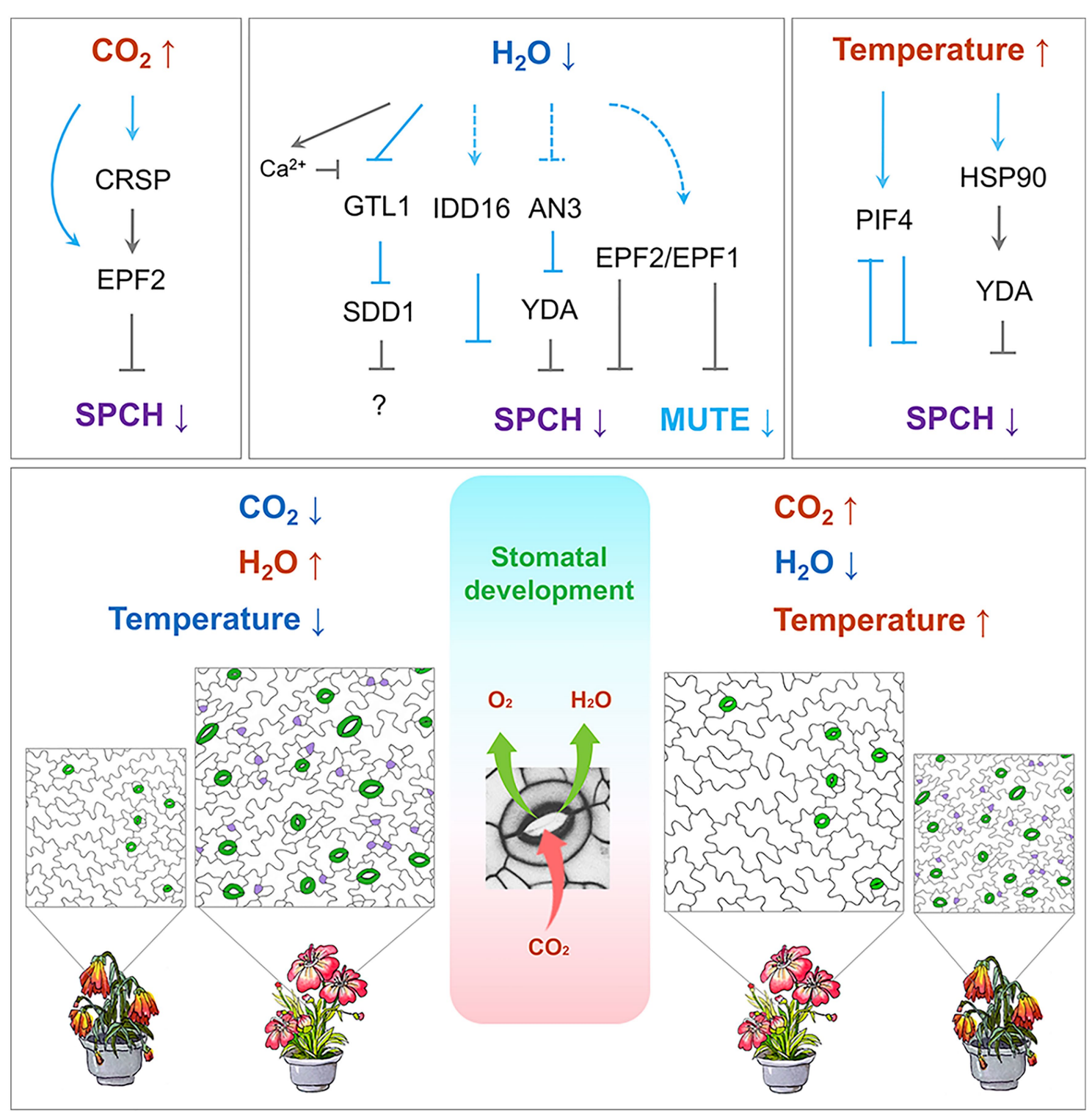

FIGURE 2 | Regulation of stomatal development by environmental cues. Top: Temperature, CO2, and water availability modulate the signaling cascade, which leads to the regulation of SPCH and MUTE. Arrows indicate positive regulation, and inverted Ts indicate negative regulation. Solid lines in light blue indicate transcriptional regulation, and solid grey lines indicate post-translational regulation. Dashed lines indicate potential regulation. Bottom: A stomate, formed by a pair of guard cells, takes up $\mathrm{CO}_{2}$ (red arrow) for photosynthesis and releases the byproduct $\mathrm{O}_{2}$ (green arrow) and water vapor (green arrow). On the left: low $\mathrm{CO}_{2}$ concentration, sufficient water supply, and ambient temperature conditions prior to the global climate change. On the right: elevated $\mathrm{CO}_{2} \mathrm{Concentration}$ deficient water supply, and increased atmospheric temperature conditions after global climate change. Stomata are highlighted in green, and meristemoids in purple. The flowering plants underneath each of the stomatal images represent the growth and stress response of the plants along with the stomatal density. Color code: blue indicates decrease; red indicates increase.

satellite stomatal formation, leading to changes in stomatal distribution on abaxial cotyledons (Haus et al., 2018; Higaki et al., 2020). A detailed molecular mechanism and the benefits for plants to have satellite stomata under high $\mathrm{CO}_{2}$ conditions are not fully understood.

\section{Water Shortage}

Water scarcity is a growing problem that correlates with global climate change. Drought conditions cause previously arable land to become unable to support crops. Increased drought conditions will cause crop yield reduction or even failure, which can result in starvation conditions for many populations. To avoid evaporative water loss, plants reduce stomatal conductance. This reduction in conductance ensures survival of the plant but causes a reduction in photosynthesis, yields, and productivity (Blum, 1996). Understanding how plants effectively use limited water resources is, therefore, crucial for future food security. Many studies on common crop plants indicate that reducing 
transpiration by decreasing stomatal density is a feasible way to increase plant drought tolerance without compromising yield (Franks et al., 2015; Hepworth et al., 2015; Wang et al., 2016; Hughes et al., 2017; Caine et al., 2019; Dunn et al., 2019; Mohammed et al., 2019).

Molecules upstream of the core pathway controlling stomatal development are the current targets for genetic manipulation. In poplar, dehydration or ABA treatment causes up-regulation of PdEPF1 (Wang et al., 2016). Overexpression of PdEPF1 consistently results in a low stomatal density, high water use efficiency, and drought tolerance (Wang et al., 2016). In creeping bentgrass, overexpression of Osa-miR393 up-regulated EPF expression. This up-regulation leads to reduced stomatal density and enhanced plant drought tolerance (Zhao et al., 2019). Similarly, overexpression of EPF2 in Arabidopsis, rice, and barley causes reduced stomatal density, decreased transpiration rate, and improved water use efficiency (Franks et al., 2015; Hepworth et al., 2015; Hughes et al., 2017; Dunn et al., 2019) (Caine et al., 2019; Mohammed et al., 2019). Reducing stomatal density by regulating EPFs, therefore, can be a promising tool for breeding crops that can better withstand drier environments without significant yield loss.

STOMATAL DENSITY AND DISTRIBUTION 1 (SDD1) could be another molecular target for improving drought tolerance in plants. Knockout mutants for SDD1 display a noticeably increased stomatal density with severe stomatal clustering (Berger and Altmann, 2000; Von Groll et al., 2002). Because SDD1 belongs to the subtilisin-like serine protease family, it has been proposed that SDD1 cleaves a precursor of a mobile peptide that negatively regulates stomatal development (Berger and Altmann, 2000; Von Groll et al., 2002). EPF1 and EPF2, however, work independently of SDD1 (Hara et al., 2007, 2009). Manipulation of SDD1 can optimize WUE and thus improve plant drought tolerance. In Arabidopsis, SDD1 expression is significantly up-regulated upon drought (Yoo et al., 2019). Overexpression of wild tomato SchSDD1 in Arabidopsis and tomato results in higher productivity under drought conditions (Morales-Navarro et al., 2018). Further, it was found that SDD1 expression is regulated by GT-2 LIKE 1 (GTL1), which is a transcription factor that binds the GT3 box in the SDD1 promoter to trans-repress its transcription (Yoo et al., 2010). GTL1 is downregulated by drought stress. In gtl1 loss-of-function mutants, SDD1 expression is significantly increased, causing a $25 \%$ reduction in stomatal density (Yoo et al., 2010). Consequently, WUE is higher and drought tolerance is enhanced (Yoo et al., 2010). The $\mathrm{Ca}^{2+}$-binding protein, calmodulin, upon binding of osmotic stress-induced $\mathrm{Ca}^{2+}$, interacts with one of the N-terminal helices of GTL1 and inhibits GTL1 binding to the SDD1 promoter. This inhibition thereby de-represses the SDD1 expression and improves WUE (Yoo et al., 2019).

GTL1 is also known to regulate trichome development. This regulation would imply a correlation between the two epidermal cell types. Indeed, WUE was higher in four tomato lines with higher trichome density. Trichome density negatively correlates with stomatal density, and the ratio of trichomes to stomata shows a strong positive correlation with WUE (Galdon-Armero et al., 2018). The same observation was also reported in a wild-type population of Arabidopsis (Simon et al., 2020). Not surprisingly, many molecules regulating trichome development also play a role in stomatal development (Torii, 2021).

Many environmental conditions have a significant effect on SPCH (Chen et al., 2020; Figures 1 and 2). Qi and colleagues found that plants with a lower concentration of $\mathrm{SPCH}$ protein exhibit significantly increases in drought tolerance (Qi et al., 2019). Overexpression of the $\mathrm{C} 2 \mathrm{H} 2$ zinc-finger transcription factor INDETERMINATE DOMAIN 16 (IDD16) caused a reduction in the $\mathrm{SPCH}$ transcription in a dose-dependent manner. The ChIP analysis indicates that IDD16 directly associates with the SPCH promoter, suggesting that $\mathrm{SPCH}$ is a direct downstream target of IDD16. In line with this, the IDD16 RNAi plants exhibit a higher stomatal density. Plants overexpressing IDD16 displayed a reduced stomatal density and were hypo-sensitive to drought stress (Qi et al., 2019).

ANGUSTIFOLIA3 (AN3) is another transcription regulator involved in drought tolerance and stomatal development (Meng and Yao, 2015). Without AN3, fewer stomata were produced, transpiration was reduced, and the plants displayed improved drought tolerance. In an3 mutants, a drastic increase was observed in the YDA transcript level. The ChIP analysis corroborated the theory that AN3 binds to the YDA promoter, indicating that $\mathrm{AN} 3$ acts as a transcriptional repressor of $Y D A$.

Overall, drought stress modulates the stomatal formation pathway almost at every step, including the peptide ligands, the MAPK cascade, and the downstream transcription factors. Interestingly, all these targets appear to be regulated at the transcriptional level, indicating that transcriptional regulation is an efficient, effective way to deal with environmental stress.

\section{High Temperature}

Responding to environmental temperature, plants adjust their cooling capacity by controlling the rate of transpiration. Besides the quick response of stomatal apertures, control of stomatal formation contributes to plant body temperature. For instance, under ambient conditions, well-watered plants with more stomata (such as epflepf2) maintain low body temperature, whereas those with fewer stomata (such as EPF1 overexpression lines) show higher body temperature (Hepworth et al., 2015; Caine et al., 2019). When water is restricted, however, EPF1 overexpression lines display more stable and lower leaf temperature than lines with a higher stomatal density. These effects are particularly notable during the reproductive stage (Hepworth et al., 2015; Caine et al., 2019; Mohammed et al., 2019). More interestingly, when the environmental temperature rises, stomatal pores of the EPF1 overexpression plants were significantly larger than those of the wild-type plants. This change allowed the plants to compensate for lower stomatal density. Plants are, therefore, dynamically balanced between evaporative cooling and water conservation. They maintain this delicate balance by regulating stomatal conductance. Plants with fewer stomata display improved initial water conservation, which allows them to more efficiently regulate stomatal movements. This improved regulation ensures adequate 
evaporative cooling even under severe drought conditions at a high temperature.

When Arabidopsis plants grown at ambient temperature $\left(22^{\circ} \mathrm{C}\right)$ are exposed to a high temperature $\left(28^{\circ} \mathrm{C}\right)$, they develop fewer stomata (Crawford et al., 2012). PHYTOCHROMEINTERACTING FACTOR 4 (PIF4) is an essential component in this process. PIF4 encodes a bHLH transcription factor involved in plant adaptation to high temperatures and is significantly up-regulated by elevated temperature $\left(28^{\circ} \mathrm{C}\right.$; Koini et al., 2009). In stomatal lineage cells, high temperature stabilizes PIF4, which in turn binds to the $S P C H$ promoter to repress its expression. This binding is responsible for inhibiting the entry of stomatal formation. Interestingly, PIF4 was identified as an SPCH target, and the transcriptome data from the seedlings in which $S P C H$ is conditionally expressed further indicate that $\mathrm{SPCH}$ protein also represses PIF4 expression. Thus, at ambient temperature, $\mathrm{SPCH}$ promotes stomatal formation while blocking PIF4 expression. When the temperature rises, PIF4 is expressed and the stabilized PIF4 protein blocks SPCH transcription by binding to its promoter, therefore inhibiting stomatal formation through negative feedback (Lau et al., 2018).

HEAT SHOCK PROTEINS 90s (HSP90s) positively regulates YDA. Thus, YDA's targets, MPK3 and MPK6, cannot be activated when HSP90s is depleted. Lack of activation results in insufficient SPCH phosphorylation and destabilization. A higher concentration of stable SPCH protein eventually leads to clustered stomata (Samakovli et al., 2020). HSP90s also affects YDA polarization via physical interaction in stomatal lineage cells. Moreover, loss-of-function mutants of YDA or HSP90s altered the transcript levels of at least $18 \mathrm{SPCH}$ target genes. This alteration indicates that the YDA-HSP90s module negatively affects the transcriptional activity of SPCH (Samakovli et al., 2020).

Similar to drought stress, heat stress modulates the stomatal entry transcription factor SPCH and the MAPK cascade. Additionally, heat stress impacts protein stability and/or function.

\section{Light}

Light, essential for growth and development, acts as an energy source and a developmental signal in plants. Stomatal development is a trait of photomorphogenesis and is positively regulated by light (Casson et al., 2009; Kang et al., 2009). Plants detect light through photoreceptors, including phytochromes and cryptochromes (Paik and Huq, 2019). Mutations in these photoreceptors cause reduced stomatal density within the corresponding light spectra (Kang et al., 2009). A common target of light signals is CONSTITUTIVE PHOTOMORPHOGENIC 1 (COP1), which is an E3 ubiquitin ligase. When COP1 is destabilized by light, it no longer activates the downstream YDA cascade, which leads to stomatal formation (Kang et al., 2009). In dark conditions, active COP1 can degrade SCRM via its E3 ubiquitin ligase activity, thereby preventing stomatal development. This pathway occurs in a YDA-independent manner and does not affect SPCH stability, suggesting a parallel pathway of COP1 that modulates the abundance of SCRM under unfavorable light conditions (Lee et al., 2017).

Additionally, light promotes stomatal formation by inducing STOMAGEN (Hronkova et al., 2015). MONOPTEROS/ARF5, a member of the AUXIN RESPONSE FACTORs family, has been reported to associate with the STOMAGEN promoter to suppress its expression (Zhang et al., 2014). Whether light exposure regulates this auxin-related MONOPTEROS is unknown. A recent study found an integration point where light signals impinge on stomatal development (Wang et al., 2021). The light-responsive HY5 plays a role in fundamental developmental processes such as photosynthetic machinery assembly, chloroplast development, pigment accumulation, and photomorphogenesis (Gangappa and Botto, 2016). The HY5 genomic binding sites have revealed its hierarchical role in the light regulation of plant development (Lee et al., 2007). Wang and colleagues found that HY5, a central transcriptional factor, directly binds to the promoter and activates STOMAGEN expression in mesophyll cells (Wang et al., 2021). HY5 is required for light regulation of SPCH. In hy5 mutants, SPCH is marginally maintained. Compromising HY5 regulation results in stomatal formation that is unresponsive to light intensity. Light-stimulated HY5 directly activates STOMAGEN expression in mesophyll cells, which in turn acts in the epidermis to stabilize SPCH. Knock-down or overexpression of STOMAGEN results in stomatal production insensitive to light intensity (Wang et al., 2021). The direct regulation of STOMAGEN expression by HY5 was also detected in a previous report by Zoulias et al. (Zoulias et al., 2020). The up-regulation of STOMAGEN by HY5 represents a regulatory mechanism of how an environmental signal is integrated into the developmental program. It provides a correlation between the $\mathrm{CO}_{2}$ uptake from stomata and the photosynthetic mesophyll cells.

\section{Nutrients}

Because nutrient uptake by roots is directly affected by transpiration, a correlation analysis of root and stomatal development in plants under drought conditions could be of interest. When plants are well watered, root area and the stomatal density are positively correlated. For example, epflepf 2 mutants have an increased number of stomata and produce a larger root system than wild-type plants and thus, display improved phosphate and nitrogen accumulation (Hepworth et al., 2016). In contrast, plants with fewer stomata, such as transgenic plants overexpressing EPF2, share comparable root hair development and have a similar phosphate uptake capacity compared to wild-type plants (Hepworth et al., 2015, 2016). When water is restricted, a large decrease in stomatal density shows no significant effect on nitrogen accumulation (Hepworth et al., 2016). High transpiration rates due to increased stomatal density promote root development under water-sufficient conditions. When water shortage occurs, this correlation is altered, which implies that there is a complex interplay between root development and stomatal density.

miRNAs play a crucial role in plant development and environmental regulation (Song et al., 2019). It is surprising, 
then, that no miRNAs appear to target known stomatal regulators, especially given the considerable number of transcriptional factors and signaling proteins that modulate stomatal development. Loss-of-function mutations in AGO1 (ARGONAUTE 1), however, drastically impact stomatal patterning and morphology of epidermal cells. This implies that miRNAs play some role in stomatal development (Yang et al., 2014). Recently, expression profiling of miRNAs in stomatal lineage cells was carried out using the cell state-specific promoters of SPCH, EPF2, MUTE, EPF1, and FAMA (Zhu et al., 2020). Most of the identified miRNAs appear to be expressed at the entry state of stomatal development and target genes involved in nutrient homeostasis, metabolism, and light response (Zhu et al., 2020). Up- or down-regulation of miRNAs results in defective stomatal patterning and density. Together with previous data, Zhu et al. suggest that stomatal lineage miRNAs and their dynamic changes constitute another layer of stomatal development regulation and may play a role in response to developmental factors, environmental cues, and nutritional status for proper lineage specification and/or progression at the entry of stomatal lineage.

Sugar status and ethylene signaling appear to fine-tune the intrinsic polarity and division potential of stomatal lineage precursor cells (Gong et al., 2021). CONSTITUTIVE TRIPLE RESPONSE (CTR1) is a core component that negatively regulates ethylene signaling. In the crt1 mutants, the stomatal-specific polar protein BREVIS RADIX-LIKE 2 (BRX2) becomes depolarized, which reduces the amplifying asymmetric division. This phenotype can be alleviated by glucose or sucrose treatment, suggesting an antagonistic effect of ethylene and sugar signaling on the self-renewing capacity of stomatal linage stem cells. Because sugar is produced by photosynthesis occurring in mesophyll cells, the effect of nutritional status and environment on the overall leaf size and epidermal patterning suggests active communication between the epidermis and mesophyll cells.

\section{CONCLUSION AND PERSPECTIVES}

Significant progress has been made in stomatal development over the past two decades. The discovery of key regulators and a core developmental pathway in stomatal lineage has contributed to the current understanding of stomatal development. Technical advances have identified genome-wide transcriptomes at the bulk-tissue, single-cell types, or singlecell level. ChIP-sequencing data of the master transcription factors are also accumulating. Despite the recent discoveries, there are open questions to be addressed: How are the stomatal lineage cells first established? How is the expression of master transcription factors initiated and coordinated at the chromatin level? How is intrinsic polarity complex targeted to the cortical membrane and integrated into the extrinsic signaling pathway? What are the molecular links between the environmental and hormonal control of stomatal development? Given the wealth of genetic resources and various types of omics data, one should explore novel factors and investigate comprehensive gene networks in stomatal lineage.
Single-cell RNA-seq can be applied to profile responses to environmental or hormonal perturbations, which could reveal whether the cell identity and cells at different developmental stages differentially respond to stress or hormone. Profiling chromatin accessibility such as Assay for Transposase Accessible Chromatin Sequencing and deoxyribonuclease I hypersensitive sequencing at the single-cell level would further the current understanding of the transcriptional program when combined with the single-cell transcriptome. Additionally, advanced livecell imaging and quantitative image analysis make it easier to keep track of lineage and monitor the cellular events at singlecell resolution, which will help to pave the way to applying the single-cell approach to crop species.

We are currently facing an environmental crisis as global climate change caused by the greenhouse gases accelerates the temperature rise and water shortage. Each of these factors will negatively impact plant ecosystems, sustainability, and food supply. Stomata can directly influence the atmospheric $\mathrm{CO}_{2}$ level, water evaporation, and even the surface temperature of the earth. Future challenges in stomatal development research, therefore, include addressing the open questions as well as translating discoveries made in Arabidopsis to agriculturally important crops. Many studies have demonstrated that stomatal morphology, density, size, distribution, and specialized cell type in grasses determine stomatal conductance. Stomatal development, then, significantly influences plant behavior in response to environmental changes. Genetic manipulation of stomatal development and physiology may contribute to better survival of plants and maintain agricultural productivity despite unfavorable conditions. Studies of stomatal development in monocots have started mostly by the comparative analysis of the genes in Arabidopsis. Because monocots bear linear arrangement of guard cells in specific cell files and four-celled stomatal complex, which enables "speedy stomata," the investigation of stomatal development and their regulation is a key to the breeding guidance. As transcriptional regulation is the major mechanism in environmental regulation on stomatal development, the rapidly responding transcription factors could form a useful toolbox for genetic manipulation. The use of CRISPR/Cas9 genome-editing technology in a cell type-specific manner could overcome deleterious effects caused by the ubiquitous disruption of essential genes. It is necessary to collect useful stomatal traits for plants to better adapt to global climate changes, which will allow us to see the outcome of current efforts.

\section{AUTHOR CONTRIBUTIONS}

$\mathrm{S}-\mathrm{KH}, \mathrm{JK}$, and $\mathrm{XQ}$ wrote the manuscript. All authors read and approved this version of the manuscript.

\section{FUNDING}

The work in the authors' laboratories was supported by grants from National Research Foundation (2019R1A2C3007376 and 
2020R1A4A1019408). S-KH was supported by the Brin Pool Program funded by the Ministry of Science and ICT through the National Research Foundation (2020H1D3A2A02110999). XQ was supported by Rutgers University.

\section{REFERENCES}

Adrian, J., Chang, J., Ballenger, C. E., Bargmann, B. O., Alassimone, J., Davies, K. A., et al. (2015). Transcriptome dynamics of the stomatal lineage: birth, amplification, and termination of a self-renewing population. Dev. Cell 33, 107-118. doi: 10.1016/j.devcel.2015.01.025

Akita, K., Hasezawa, S., and Higaki, T. (2013). Breaking of plant stomatal one-cell-spacing rule by sugar solution immersion. PLoS One 8:e72456. doi: 10.1371/journal.pone.0072456

Amsbury, S., Hunt, L., Elhaddad, N., Baillie, A., Lundgren, M., Verhertbruggen, Y., et al. (2016). Stomatal function requires pectin De-methyl-esterification of the guard Cell Wall. Curr. Biol. 26, 2899-2906. doi: 10.1016/j.cub.2016.08.021

Berger, D., and Altmann, T. (2000). A subtilisin-like serine protease involved in the regulation of stomatal density and distribution in Arabidopsis thaliana. Genes Dev. 14, 1119-1131

Bergmann, D. C., Lukowitz, W., and Somerville, C. R. (2004). Stomatal development and pattern controlled by a MAPKK kinase. Science 304, 1494-1497. doi: 10.1126/science.1096014

Bian, C., Guo, X., Zhang, Y., Wang, L., Xu, T., DeLong, A., et al (2020). Protein phosphatase $2 \mathrm{~A}$ promotes stomatal development by stabilizing SPEECHLESS in Arabidopsis. Proc. Natl. Acad. Sci. 117, 13127-13137. doi: 10.1073/pnas.1912075117

Blum, A. (1996). Crop responses to drought and the interpretation of adaptation. Plant Growth Regul. 20, 135-148. doi: 10.1007/BF00024010

Buckley, C. R., Caine, R. S., and Gray, J. E. (2019). Pores for thought: can genetic manipulation of stomatal density protect future Rice yields? Front. Plant Sci. 10:1783. doi: 10.3389/fpls.2019.01783

Caine, R. S., Chater, C. C., Kamisugi, Y., Cuming, A. C., Beerling, D. J., Gray, J. E., et al. (2016). An ancestral stomatal patterning module revealed in the non-vascular land plant Physcomitrella patens. Development 143, 3306-3314. doi: 10.1242/dev.135038

Caine, R. S., Yin, X., Sloan, J., Harrison, E. L., Mohammed, U., Fulton, T., et al. (2019). Rice with reduced stomatal density conserves water and has improved drought tolerance under future climate conditions. New Phytol. 221, 371-384. doi: 10.1111/nph.15344

Cartwright, H. N., Humphries, J. A., and Smith, L. G. (2009). PAN1: a receptorlike protein that promotes polarization of an asymmetric cell division in maize. Science 323, 649-651. doi: 10.1126/science.1161686

Casson, S. A., Franklin, K. A., Gray, J. E., Grierson, C. S., Whitelam, G. C., and Hetherington, A. M. (2009). Phytochrome B and PIF4 regulate stomatal development in response to light quantity. Curr. Biol. 19, 229-234. doi: 10.1016/j.cub.2008.12.046

Castorina, G., Fox, S., Tonelli, C., Galbiati, M., and Conti, L. (2016). A novel role for STOMATAL CARPENTER 1 in stomata patterning. BMC Plant Biol. 16, 172. doi: 10.1186/s12870-016-0851-Z

Chen, Z. H., Chen, G., Dai, F., Wang, Y., Hills, A., Ruan, Y. L., et al. (2017). Molecular evolution of grass stomata. Trends Plant Sci. 22, 124-139. doi: 10.1016/j.tplants.2016.09.005

Chen, L., Guan, L., Qian, P., Xu, F., Wu, Z., Wu, Y., et al. (2016). NRPB3, the third largest subunit of RNA polymerase II, is essential for stomatal patterning and differentiation in Arabidopsis. Development 143, 1600-1611. doi: $10.1242 /$ dev. 129098

Chen, L., Wu, Z., and Hou, S. (2020). SPEECHLESS speaks loudly in stomatal development. Front. Plant Sci. 11:114. doi: 10.3389/fpls.2020.00114

Chen, L., Zhao, M., Wu, Z., Chen, S., Rojo, E., Luo, J., et al. (2021). RNA polymerase II associated proteins regulate stomatal development through direct interaction with stomatal transcription factors in Arabidopsis thaliana. New Phytol. 230, 171-189. doi: 10.1111/nph.17004

Conklin, P. A., Strable, J., Li, S., and Scanlon, M. J. (2019). On the mechanisms of development in monocot and eudicot leaves. New Phytol. 221, 706-724. doi: $10.1111 / \mathrm{nph} .15371$

\section{ACKNOWLEDGMENTS}

We would like to thank $\mathrm{Shu} \mathrm{Wu}$ for providing the flower artwork in Figure 2.

Crawford, A. J., McLachlan, D. H., Hetherington, A. M., and Franklin, K. A. (2012). High temperature exposure increases plant cooling capacity. Curr. Biol. 22, R396-R397. doi: 10.1016/j.cub.2012.03.044

Davies, K. A., and Bergmann, D. C. (2014). Functional specialization of stomatal bHLHs through modification of DNA-binding and phosphoregulation potential. Proc. Natl. Acad. Sci. 111, 15585-15590. doi: 10.1073/pnas.1411766111

Dow, G. J., and Bergmann, D. C. (2014). Patterning and processes: how stomatal development defines physiological potential. Curr. Opin. Plant Biol. 21, 67-74. doi: $10.1016 /$ j.pbi.2014.06.007

Duckett, J. G., and Pressel, S. (2018). The evolution of the stomatal apparatus: intercellular spaces and sporophyte water relations in bryophytes-two ignored dimensions. Philos. Trans. R. Soc. Lond. Ser. B Biol. Sci. 373:20160498. doi: 10.1098/rstb.2016.0498

Dunn, J., Hunt, L., Afsharinafar, M., Meselmani, M. A., Mitchell, A., Howells, R., et al. (2019). Reduced stomatal density in bread wheat leads to increased water-use efficiency. J. Exp. Bot. 70, 4737-4748. doi: 10.1093/jxb/erz248

Engineer, C. B., Ghassemian, M., Anderson, J. C., Peck, S. C., Hu, H., and Schroeder, J. I. (2014). Carbonic anhydrases, EPF2 and a novel protease mediate CO2 control of stomatal development. Nature 513, 246-250. doi: $10.1038 /$ nature 13452

Facette, M. R., Park, Y., Sutimantanapi, D., Luo, A., Cartwright, H. N., Yang, B., et al. (2015). The SCAR/WAVE complex polarizes PAN receptors and promotes division asymmetry in maize. Nat Plants 1, 1-8. doi: 10.1038/nplants.2014.24

Facette, M. R., and Smith, L. G. (2012). Division polarity in developing stomata. Curr. Opin. Plant Biol. 15, 585-592. doi: 10.1016/j.pbi.2012.09.013

Franks, P. J. W., Doheny-Adams, T., Britton-Harper, Z. J., and Gray, J. E. (2015). Increasing water-use efficiency directly through genetic manipulation of stomatal density. New Phytol. 207, 188-195. doi: 10.1111/nph.13347

Galdon-Armero, J., Fullana-Pericas, M., Mulet, P. A., Conesa, M. A., Martin, C., and Galmes, J. (2018). The ratio of trichomes to stomata is associated with water use efficiency in Solanum lycopersicum (tomato). Plant J. 96, 607-619. doi: $10.1111 /$ tpj.14055

Gangappa, S. N., and Botto, J. F. (2016). The multifaceted roles of HY5 in plant growth and development. Mol. Plant 9, 1353-1365. doi: 10.1016/j. molp.2016.07.002

Geisler, M., Yang, M., and Sack, F. D. (1998). Divergent regulation of stomatal initiation and patterning in organ and suborgan regions of the Arabidopsis mutants too many mouths and four lips. Planta 205, 522-530. doi: 10.1007/ s004250050351

Gong, Y., Alassimone, J., Varnau, R., Sharma, N., Cheung, L. S., and Bergmann, D. C. (2021). Tuning self-renewal in the Arabidopsis stomatal lineage by hormone and nutrient regulation of asymmetric cell division. elife 10:e63335. doi: 10.7554/eLife.63335

Grones, P., Majda, M., Doyle, S. M., Van Damme, D., and Robert, S. (2020). Fluctuating auxin response gradients determine pavement cell-shape acquisition. Proc. Natl. Acad. Sci. 117, 16027-16034. doi: 10.1073/pnas.2007400117

Gudesblat, G. E., Schneider-Pizon, J., Betti, C., Mayerhofer, J., Vanhoutte, I., van Dongen, W., et al. (2012). SPEECHLESS integrates brassinosteroid and stomata signalling pathways. Nat. Cell Biol. 14, 548-554. doi: 10.1038/ncb2471

Guo, X., and Dong, J. (2019). To divide or differentiate: it is about scaffolding. Trends Plant Sci. 24, 481-484. doi: 10.1016/j.tplants.2019.03.007

Guo, X., Park, C. H., Wang, Z. Y., Nickels, B. E., and Dong, J. (2021a). A spatiotemporal molecular switch governs plant asymmetric cell division. Nat Plants 7, 667-680. doi: 10.1038/s41477-021-00906-0

Guo, X., Wang, L., and Dong, J. (2021b). Establishing asymmetry: stomatal division and differentiation in plants. New Phytol. 232, 60-67. doi: 10.1111/ nph.17613

Hachez, C., Ohashi-Ito, K., Dong, J., and Bergmann, D. C. (2011). Differentiation of Arabidopsis guard cells: analysis of the networks incorporating the basic helix-loop-helix transcription factor, FAMA. Plant Physiol. 155, 1458-1472. doi: $10.1104 /$ pp.110.167718 
Han, C., Liu, Y., Shi, W., Qiao, Y., Wang, L., Tian, Y., et al. (2020). KIN10 promotes stomatal development through stabilization of the SPEECHLESS transcription factor. Nat. Commun. 11, 1-10. doi: 10.1038/s41467-02018048-w

Han, S. K., Qi, X., Sugihara, K., Dang, J. H., Endo, T. A., Miller, K. L., et al. (2018). MUTE directly orchestrates cell-state switch and the single symmetric division to create stomata. Dev. Cell 45, 303-315 e305. doi: 10.1016/j. devcel.2018.04.010

Han, S. K., and Torii, K. U. (2016). Lineage-specific stem cells, signals and asymmetries during stomatal development. Development 143, 1259-1270. doi: $10.1242 /$ dev. 127712

Hara, K., Kajita, R., Torii, K. U., Bergmann, D. C., and Kakimoto, T. (2007). The secretory peptide gene EPF1 enforces the stomatal one-cell-spacing rule. Genes Dev. 21, 1720-1725. doi: 10.1101/gad.1550707

Hara, K., Yokoo, T., Kajita, R., Onishi, T., Yahata, S., Peterson, K. M., et al. (2009). Epidermal cell density is autoregulated via a secretory peptide, EPIDERMAL PATTERNING FACTOR 2 in Arabidopsis leaves. Plant Cell Physiol. 50, 1019-1031. doi: 10.1093/pcp/pcp068

Hatfield, L. J., and Prueger, H. J. (2015). Temperature extremes: effect on plant growth and development. Weather and Climate Extremes 10, 4-10. doi: 10.1016/j.wace.2015.08.001

Haus, M. J., Li, M., Chitwood, D. H., and Jacobs, T. W. (2018). Long-distance and trans-generational stomatal patterning by $\mathrm{CO} 2$ Across Arabidopsis organs. Front. Plant Sci. 9:1714. doi: 10.3389/fpls.2018.01714

Hecker, A., Brand, L. H., Peter, S., Simoncello, N., Kilian, J., Harter, K., et al. (2015). The Arabidopsis GAGA-binding factor BASIC PENTACYSTEINE6 recruits the POLYCOMB-REPRESSIVE COMPLEX1 component LIKE HETEROCHROMATIN PROTEIN1 to GAGA DNA motifs. Plant Physiol. 168, 1013-1024. doi: 10.1104/pp.15.00409

Hepworth, C., Caine, R. S., Harrison, E. L., Sloan, J., and Gray, J. E. (2018). Stomatal development: focusing on the grasses. Curr. Opin. Plant Biol. 41, 1-7. doi: 10.1016/j.pbi.2017.07.009

Hepworth, C., Doheny-Adams, T., Hunt, L., Cameron, D. D., and Gray, J. E. (2015). Manipulating stomatal density enhances drought tolerance without deleterious effect on nutrient uptake. New Phytol. 208, 336-341. doi: 10.1111/ nph.13598

Hepworth, C., Turner, C., Landim, M. G., Cameron, D., and Gray, J. E. (2016). Balancing water uptake and loss through the coordinated regulation of stomatal and root development. PLoS One 11:e0156930. doi: 10.1371/journal. pone. 0156930

Herrmann, A., and Torii, K. U. (2020). Shouting out loud: Signaling modules in the regulation of stomatal development. Plant Physiol. 185, 765-780. doi: 10.1093/plphys/kiaa061

Higaki, T., Akita, K., and Hasezawa, S. (2020). Elevated CO2 promotes satellite stomata production in young cotyledons of Arabidopsis thaliana. Genes Cells 25, 475-482. doi: 10.1111/gtc.12773

Ho, C. K., Bringmann, M., Oshima, Y., Mitsuda, N., and Bergmann, D. C. (2021). Transcriptional profiling reveals signatures of latent developmental potential in Arabidopsis stomatal lineage ground cells. Proc. Natl. Acad. Sci. 118:e2021682118. doi: 10.1073/pnas.2021682118

Horst, R. J., Fujita, H., Lee, J. S., Rychel, A. L., Garrick, J. M., Kawaguchi, M., et al. (2015). Molecular framework of a regulatory circuit initiating twodimensional spatial patterning of stomatal lineage. PLoS Genet. 11:e1005374. doi: 10.1371/journal.pgen.1005374

Houbaert, A., Zhang, C., Tiwari, M., Wang, K., de Marcos Serrano, A., Savatin, D. V., et al. (2018). POLAR-guided signalling complex assembly and localization drive asymmetric cell division. Nature 563, 574-578. doi: 10.1038/s41586-018-0714-x

Hronkova, M., Wiesnerova, D., Simkova, M., Skupa, P., Dewitte, W., Vrablova, M., et al. (2015). Light-induced STOMAGEN-mediated stomatal development in Arabidopsis leaves. J. Exp. Bot. 66, 4621-4630. doi: 10.1093/jxb/erv233

Hu, H., Boisson-Dernier, A., Israelsson-Nordstrom, M., Bohmer, M., Xue, S., Ries, A., et al. (2010). Carbonic anhydrases are upstream regulators of CO2-controlled stomatal movements in guard cells. Nat. Cell Biol. 12, 87-93. doi: $10.1038 /$ ncb2009

Hughes, J., Hepworth, C., Dutton, C., Dunn, J. A., Hunt, L., Stephens, J., et al. (2017). Reducing stomatal density in barley improves drought tolerance without impacting on yield. Plant Physiol. 174, 776-787. doi: 10.1104/ pp. 16.01844
Hunt, L., and Gray, J. E. (2009). The signaling peptide EPF2 controls asymmetric cell divisions during stomatal development. Curr. Biol. 19, 864-869. doi: 10.1016/j.cub.2009.03.069

John, P. C., and Qi, R. (2008). Cell division and endoreduplication: doubtful engines of vegetative growth. Trends Plant Sci. 13, 121-127. doi: 10.1016/j. tplants.2008.01.004

Kanaoka, M. M., Pillitteri, L. J., Fujii, H., Yoshida, Y., Bogenschutz, N. L., Takabayashi, J., et al. (2008). SCREAM/ICE1 and SCREAM2 specify three cell-state transitional steps leading to arabidopsis stomatal differentiation. Plant Cell 20, 1775-1785. doi: 10.1105/tpc.108.060848

Kang, C. Y., Lian, H. L., Wang, F. F., Huang, J. R., and Yang, H. Q. (2009). Cryptochromes, phytochromes, and COP1 regulate light-controlled stomatal development in Arabidopsis. Plant Cell 21, 2624-2641. doi: 10.1105/ tpc. 109.069765

Klermund, C., Ranftl, Q. L., Diener, J., Bastakis, E., Richter, R., and Schwechheimer, C. (2016). LLM-Domain B-GATA transcription factors promote stomatal development downstream of light Signaling pathways in Arabidopsis thaliana hypocotyls. Plant Cell 28, 646-660. doi: 10.1105/ tpc. 15.00783

Koini, M. A., Alvey, L., Allen, T., Tilley, C. A., Harberd, N. P., Whitelam, G. C., et al. (2009). High temperature-mediated adaptations in plant architecture require the bHLH transcription factor PIF4. Curr. Biol. 19, 408-413. doi: 10.1016/j.cub.2009.01.046

Kondo, T., Kajita, R., Miyazaki, A., Hokoyama, M., Nakamura-Miura, T., Mizuno, S., et al. (2010). Stomatal density is controlled by a mesophyllderived signaling molecule. Plant Cell Physiol. 51, 1-8. doi: 10.1093/pcp/ pcp 180

Lampard, G. R., Macalister, C. A., and Bergmann, D. C. (2008). Arabidopsis stomatal initiation is controlled by MAPK-mediated regulation of the bHLH SPEECHLESS. Science 322, 1113-1116. doi: 10.1126/science.1162263

Lau, O. S., Davies, K. A., Chang, J., Adrian, J., Rowe, M. H., Ballenger, C. E., et al. (2014). Direct roles of SPEECHLESS in the specification of stomatal self-renewing cells. Science 345, 1605-1609. doi: 10.1126/science. 1256888

Lau, O. S., Song, Z., Zhou, Z., Davies, K. A., Chang, J., Yang, X., et al. (2018). Direct control of SPEECHLESS by PIF4 in the high-temperature response of stomatal development. Curr. Biol. 28, 1273-1280 e1273. doi: 10.1016/j. cub.2018.02.054

Lee, L. R., and Bergmann, D. C. (2019). The plant stomatal lineage at a glance. J. Cell Sci. 132:jcs228551. doi: 10.1242/jcs.228551

Lee, J., He, K., Stolc, V., Lee, H., Figueroa, P., Gao, Y., et al. (2007). Analysis of transcription factor HY5 genomic binding sites revealed its hierarchical role in light regulation of development. Plant Cell 19, 731-749. doi: 10.1105/ tpc. 106.047688

Lee, J. S., Hnilova, M., Maes, M., Lin, Y. C., Putarjunan, A., Han, S. K., et al. (2015). Competitive binding of antagonistic peptides fine-tunes stomatal patterning. Nature 522, 439-443. doi: 10.1038/nature14561

Lee, J. H., Jung, J. H., and Park, C. M. (2017). Light inhibits COP1-mediated degradation of ICE transcription factors to induce stomatal development in Arabidopsis. Plant Cell 29, 2817-2830. doi: 10.1105/tpc.17.00371

Lee, J. S., Kuroha, T., Hnilova, M., Khatayevich, D., Kanaoka, M. M., McAbee, J. M., et al. (2012). Direct interaction of ligand-receptor pairs specifying stomatal patterning. Genes Dev. 26, 126-136. doi: 10.1101/gad.179895.111

Lee, E., Lucas, J. R., Goodrich, J., and Sack, F. D. (2014a). Arabidopsis guard cell integrity involves the epigenetic stabilization of the FLP and FAMA transcription factor genes. Plant J. 78, 566-577. doi: 10.1111/ tpj. 12516

Lee, E., Lucas, J. R., and Sack, F. D. (2014b). Deep functional redundancy between FAMA and FOUR LIPS in stomatal development. Plant J. 78, 555-565. doi: 10.1111/tpj.12489

Lee, L. R., Wengier, D. L., and Bergmann, D. C. (2019). Cell-type-specific transcriptome and histone modification dynamics during cellular reprogramming in the Arabidopsis stomatal lineage. Proc. Natl. Acad. Sci. 116, 21914-21924. doi: 10.1073/pnas.1911400116

Lin, G., Zhang, L., Han, Z., Yang, X., Liu, W., Li, E., et al. (2017). A receptorlike protein acts as a specificity switch for the regulation of stomatal development. Genes Dev. 31, 927-938. doi: 10.1101/gad.297580.117

Lindsey, R. (2020). Climate Change: Atomospheric Carbon Dioxide. NOAA. Climate.gov. https://www.climate.gov/print/8431 
Liu, T., Ohashi-Ito, K., and Bergmann, D. C. (2009). Orthologs of Arabidopsis thaliana stomatal bHLH genes and regulation of stomatal development in grasses. Development 136, 2265-2276. doi: 10.1242/dev.032938

Liu, Z., Zhou, Y., Guo, J., Li, J., Tian, Z., Zhu, Z., et al. (2020). Global dynamic molecular profiling of stomatal lineage cell development by single-cell RNA sequencing. Mol. Plant 13, 1178-1193. doi: 10.1016/j.molp.2020.06.010

Long, J. A., Ohno, C., Smith, Z. R., and Meyerowitz, E. M. (2020). TOPLESS regulates apical embryonic fate in Arabidopsis. Science 312, 1520-1523. doi: 10.1126/science.1123841

Lopez-Anido, C. B., Vaten, A., Smoot, N. K., Sharma, N., Guo, V., Gong, Y., et al. (2021). Single-cell resolution of lineage trajectories in the Arabidopsis stomatal lineage and developing leaf. Dev. Cell 56, 1043-1055 e1044. doi: 10.1016/j.devcel.2021.03.014

MacAlister, C. A., Ohashi-Ito, K., and Bergmann, D. C. (2007). Transcription factor control of asymmetric cell divisions that establish the stomatal lineage. Nature 445, 537-540. doi: 10.1038/nature05491

Mair, A., Xu, S. L., Branon, T. C., Ting, A. Y., and Bergmann, D. C. (2019). Proximity labeling of protein complexes and cell-type-specific organellar proteomes in Arabidopsis enabled by TurboID. elife 8:e47864. doi: 10.7554/ eLife.47864

Matos, J. L., Lau, O. S., Hachez, C., Cruz-Ramirez, A., Scheres, B., and Bergmann, D. C. (2014). Irreversible fate commitment in the Arabidopsis stomatal lineage requires a FAMA and RETINOBLASTOMA-RELATED module. elife 3:e03271. doi: 10.7554/eLife.03271

McElwain, J. C., and Steinthorsdottir, M. (2017). Paleoecology, ploidy, Paleoatmospheric composition, and developmental biology: A review of the multiple uses of fossil stomata. Plant Physiol. 174, 650-664. doi: 10.1104/ pp.17.00204

McKown, K. H., and Bergmann, D. C. (2020). Stomatal development in the grasses: lessons from models and crops (and crop models). New Phytol. 227, 1636-1648. doi: 10.1111/nph.16450

Meng, L. S., and Yao, S. Q. (2015). Transcription co-activator Arabidopsis ANGUSTIFOLIA3 (AN3) regulates water-use efficiency and drought tolerance by modulating stomatal density and improving root architecture by the transrepression of YODA (YDA). Plant Biotechnol. J. 13, 893-902. doi: $10.1111 /$ pbi.12324

Mohammed, U., Caine, R. S., Atkinson, J. A., Harrison, E. L., Wells, D., Chater, C. C., et al. (2019). Rice plants overexpressing OsEPF1 show reduced stomatal density and increased root cortical aerenchyma formation. Sci. Rep. 9, 1-13. doi: 10.1038/s41598-019-41922-7

Morales-Navarro, S., Pérez-Díaz, R., Ortega, A., de Marcos, A., Mena, M., Fenoll, C., et al. (2018). Overexpression of a SDD1-Like Gene From wild tomato decreases stomatal density and enhances dehydration avoidance in Arabidopsis and cultivated tomato. Front. Plant Sci. 9:940. doi: 10.3389/ fpls.2018.00940

Mu, Y., Zou, M., Sun, X., He, B., Xu, X., Liu, Y., et al. (2017). BASIC PENTACYSTEINE proteins repress ABSCISIC ACID INSENSITIVE4 expression via direct recruitment of the Polycomb-repressive complex 2 in Arabidopsis root development. Plant Cell Physiol. 58, 607-621. doi: $10.1093 / \mathrm{pcp} / \mathrm{pcx} 006$

Negi, J., Moriwaki, K., Konishi, M., Yokoyama, R., Nakano, T., Kusumi, K., et al. (2013). A Dof transcription factor, SCAP1, is essential for the development of functional stomata in Arabidopsis. Curr. Biol. 23, 479-484. doi: 10.1016/j. cub.2013.02.001

Nunes, T. D. G., Zhang, D., and Raissig, M. T. (2020). Form, development and function of grass stomata. Plant J. 101, 780-799. doi: 10.1111/tpj.14552

Ohashi-Ito, K., and Bergmann, D. C. (2006). Arabidopsis FAMA controls the final proliferation/differentiation switch during stomatal development. Plant Cell 18, 2493-2505. doi: 10.1105/tpc.106.046136

Ohki, S., Takeuchi, M., and Mori, M. (2011). The NMR structure of stomagen reveals the basis of stomatal density regulation by plant peptide hormones. Nat. Commun. 2, 1-7. doi: 10.1038/ncomms 1520

Paik, I., and Huq, E. (2019). Plant photoreceptors: multi-functional sensory proteins and their signaling networks. Semin. Cell Dev. Biol. 92, 114-121. doi: $10.1016 /$ j.semcdb.2019.03.007

Pillitteri, L. J., Peterson, K. M., Horst, R. J., and Torii, K. U. (2011). Molecular profiling of stomatal meristemoids reveals new component of asymmetric cell division and commonalities among stem cell populations in Arabidopsis. Plant Cell 23, 3260-3275. doi: 10.1105/tpc.111.088583
Pillitteri, L. J., Sloan, D. B., Bogenschutz, N. L., and Torii, K. U. (2007). Termination of asymmetric cell division and differentiation of stomata. Nature 445, 501-505. doi: 10.1038/nature05467

Putarjunan, A., Ruble, J., Srivastava, A., Zhao, C., Rychel, A. L., Hofstetter, A. K., et al. (2019). Bipartite anchoring of SCREAM enforces stomatal initiation by coupling MAP kinases to SPEECHLESS. Nat Plants 5, 742-754. doi: 10.1038/s41477-019-0440-x

Qi, X., Han, S. K., Dang, J. H., Garrick, J. M., Ito, M., Hofstetter, A. K., et al. (2017). Autocrine regulation of stomatal differentiation potential by EPF1 and ERECTA-LIKE1 ligand-receptor signaling. elife 6:24102. doi: 10.7554/ eLife. 24102

Qi, S. L., Lin, Q. F., Feng, X. J., Han, H. L., Liu, J., Zhang, L., et al. (2019). IDD16 negatively regulates stomatal initiation via trans-repression of SPCH in Arabidopsis. Plant Biotechnol. J. 17, 1446-1457. doi: 10.1111/pbi.13070

Qi, X., and Torii, K. U. (2018). Hormonal and environmental signals guiding stomatal development. BMC Biol. 16, 21. doi: 10.1186/s12915-018-0488-5

Qi, X., Yoshinari, A., Bai, P., Maes, M., Zeng, S. M., and Torii, K. U. (2020). The manifold actions of signaling peptides on subcellular dynamics of a receptor specify stomatal cell fate. elife 9:e58097. doi: 10.7554/ eLife. 58097

Raissig, M. T., Abrash, E., Bettadapur, A., Vogel, J. P., and Bergmann, D. C. (2016). Grasses use an alternatively wired bHLH transcription factor network to establish stomatal identity. Proc. Natl. Acad. Sci. 113, 8326-8331. doi: 10.1073/pnas. 1606728113

Raissig, M. T., Matos, J. L., Anleu Gil, M. X., Kornfeld, A., Bettadapur, A., Abrash, E., et al. (2017). Mobile MUTE specifies subsidiary cells to build physiologically improved grass stomata. Science $355,1215-1218$. doi: 10.1126/ science.aal 3254

Robinson, S., Barbier de Reuille, P., Chan, J., Bergmann, D., Prusinkiewicz, P., and Coen, E. (2011). Generation of spatial patterns through cell polarity switching. Science 333, 1436-1440. doi: 10.1126/science.1202185

Rowe, M. H., and Bergmann, D. C. (2010). Complex signals for simple cells: the expanding ranks of signals and receptors guiding stomatal development. Curr. Opin. Plant Biol. 13, 548-555. doi: 10.1016/j.pbi.2010.06.002

Rychel, A. L., Peterson, K. M., and Torii, K. U. (2010). Plant twitter: ligands under 140 amino acids enforcing stomatal patterning. J. Plant Res. 123 275-280. doi: 10.1007/s10265-010-0330-9

Sage, R. F., and Coleman, J. R. (2001). Effects of low atmospheric $\mathrm{CO}(2)$ on plants: more than a thing of the past. Trends Plant Sci. 6, 18-24. doi: 10.1016/S1360-1385(00)01813-6

Samakovli, D., Ticha, T., Vavrdova, T., Ovecka, M., Luptovciak, I., Zapletalova, V., et al. (2020). YODA-HSP90 module regulates phosphorylation-dependent inactivation of SPEECHLESS to control stomatal development under acute heat stress in Arabidopsis. Mol. Plant 13, 612-633. doi: 10.1016/j. molp.2020.01.001

Simon, N. M. L., Sugisaka, J., Honjo, M. N., Tunstad, S. A., Tunna, G., Kudoh, H., et al. (2020). Altered stomatal patterning accompanies a trichome dimorphism in a natural population of. Plant Direct 4:e00262. doi: 10.1002/pld3.262

Song, X., Li, Y., Cao, X., and Qi, Y. (2019). MicroRNAs and their regulatory roles in plant-environment interactions. Annu. Rev. Plant Biol. 70, 489-525. doi: 10.1146/annurev-arplant-050718-100334

Sugano, S. S., Shimada, T., Imai, Y., Okawa, K., Tamai, A., Mori, M., et al. (2010). Stomagen positively regulates stomatal density in Arabidopsis. Nature 463, 241-244. doi: 10.1038/nature08682

Tamnanloo, F., Damen, H., Jangra, R., and Lee, J. S. (2018). MAP KINASE PHOSPHATASE1 controls cell fate transition during stomatal development. Plant Physiol. 178, 247-257. doi: 10.1104/pp.18.00475

Torii, K. U. (2012). Mix-and-match: ligand-receptor pairs in stomatal development and beyond. Trends Plant Sci. 17, 711-719. doi: 10.1016/j.tplants.2012.06.013

Torii, K. U. (2021). Stomatal development in the context of epidermal tissues. Ann. Bot. 128, 137-148. doi: 10.1093/aob/mcab052

Trivino, M., Martin-Trillo, M., Ballesteros, I., Delgado, D., de Marcos, A., Desvoyes, B., et al. (2013). Timely expression of the Arabidopsis stoma-fate master regulator MUTE is required for specification of other epidermal cell types. Plant J. 75, 808-822. doi: $10.1111 /$ tpj.12244

Vaten, A., Soyars, C. L., Tarr, P. T., Nimchuk, Z. L., and Bergmann, D. C. (2018). Modulation of asymmetric division diversity through Cytokinin and SPEECHLESS regulatory interactions in the Arabidopsis stomatal lineage. Dev. Cell 47, 53-66. doi: 10.1016/j.devcel.2018.08.007 
Von Groll, U., Berger, D., and Altmann, T. (2002). The subtilisin-like serine protease SDD1 mediates cell-to-cell signaling during Arabidopsis stomatal development. Plant Cell 14, 1527-1539. doi: 10.1105/tpc.001016

Wang, H., Guo, S., Qiao, X., Guo, J., Li, Z., Zhou, Y., et al. (2019). BZU2/ ZmMUTE controls symmetrical division of guard mother cell and specifies neighbor cell fate in maize. PLoS Genet. 15:e1008377. doi: 10.1371/journal. pgen. 1008377

Wang, C., Liu, S., Dong, Y., Zhao, Y., Geng, A., Xia, X., et al. (2016). PdEPF1 regulates water-use efficiency and drought tolerance by modulating stomatal density in poplar. Plant Biotechnol. J. 14, 849-860. doi: 10.1111/pbi.12434

Wang, H., Ngwenyama, N., Liu, Y., Walker, J. C., and Zhang, S. (2007). Stomatal development and patterning are regulated by environmentally responsive mitogen-activated protein kinases in Arabidopsis. Plant Cell 19, 63-73. doi: 10.1105/tpc.106.048298

Wang, S., Zhou, Z., Rahiman, R., Lee, G. S. Y., Yeo, Y. K., Yang, X., et al. (2021). Light regulates stomatal development by modulating paracrine signaling from inner tissues. Nat. Commun. 12, 1-13. doi: 10.1038/ s41467-021-23728-2

Wu, Z., Chen, L., Yu, Q., Zhou, W., Gou, X., Li, J., et al. (2019). Multiple transcriptional factors control stomata developmentin rice. New Phytol. 223, 220-232. doi: 10.1111/nph.15766

Xiao, J., Jin, R., Yu, X., Shen, M., Wagner, J. D., Pai, A., et al. (2017). Cis and trans determinants of epigenetic silencing by Polycomb repressive complex 2 in Arabidopsis. Nat. Genet. 49, 1546-1552. doi: 10.1038/ng.3937

Xie, Z., Lee, E., Lucas, J. R., Morohashi, K., Li, D., Murray, J. A., et al. (2010). Regulation of cell proliferation in the stomatal lineage by the Arabidopsis MYB FOUR LIPS via direct targeting of core cell cycle genes. Plant Cell 22, 2306-2321. doi: 10.1105/tpc.110.074609

Yang, K., Jiang, M., and Le, J. (2014). A new loss-of-function allele 28y reveals a role of ARGONAUTE1 in limiting asymmetric division of stomatal lineage ground cell. J. Integr. Plant Biol. 56, 539-549. doi: 10.1111/jipb.12154

Yang, K. Z., Jiang, M., Wang, M., Xue, S., Zhu, L. L., Wang, H. Z., et al. (2015). Phosphorylation of serine 186 of bHLH transcription factor SPEECHLESS promotes stomatal development in Arabidopsis. Mol. Plant 8, 783-795. doi: 10.1016/j.molp.2014.12.014

Yang, K., Zhu, L., Wang, H., Jiang, M., Xiao, C., Hu, X., et al. (2019). A conserved but plant-specific CDK-mediated regulation of DNA replication protein A2 in the precise control of stomatal terminal division. Proc. Natl. Acad. Sci. 116, 18126-18131. doi: 10.1073/pnas.1819345116

Yoo, C. Y., Mano, N., Finkler, A., Weng, H., Day, I. S., Reddy, A. S. N., et al. (2019). A Ca. Sci. Rep. 9:12282. doi: 10.1038/s41598-019-47529-2
Yoo, C. Y., Pence, H. E., Jin, J. B., Miura, K., Gosney, M. J., Hasegawa, P. M., et al. (2010). The Arabidopsis GTL1 transcription factor regulates water use efficiency and drought tolerance by modulating stomatal density via transrepression of SDD1. Plant Cell 22, 4128-4141. doi: 10.1105/ tpc. 110.078691

Zhang, U., He, S. B., Li, L., and Yang, H. Q. (2002). The subtilisin-like serine protease SDD1 mediates cell-to-cell signaling during Arabidopsis stomatal development. Proc. Natl. Acad. Sci. 111, 3015-3023. doi: 10.1073/ pnas. 1400542111

Zhang, J. Y., Guo, X., and Dong, J. (2016). Auxin inhibits stomatal development through MONOPTEROS repression of a mobile peptide gene STOMAGEN in mesophyll. Curr. Biol. 26, 2957-2965. doi: 10.1016/j.cub.2016.08.066

Zhang, Y., Wang, P., Shao, W., Zhu, J. K., and Dong, J. (2015). The BASL polarity protein controls a MAPK signaling feedback loop in asymmetric cell division. Dev. Cell 33, 136-149. doi: 10.1016/j.devcel.2015.02.022

Zhao, J., Yuan, S., Zhou, M., Yuan, N., Li, Z., Hu, Q., et al. (2019). Transgenic creeping bentgrass overexpressing Osa-miR393a exhibits altered plant development and improved multiple stress tolerance. Plant Biotechnol. J. 17, 233-251. doi: 10.1111/pbi.12960

Zhu, J., Park, J. H., Lee, S., Lee, J. H., Hwang, D., Kwak, J. M., et al. (2020). Regulation of stomatal development by stomatal lineage miRNAs. Proc. Natl. Acad. Sci. 117, 6237-6245. doi: 10.1073/pnas.1919722117

Zoulias, N., Brown, J., Rowe, J., and Casson, S. A. (2020). HY5 is not integral to light mediated stomatal development in Arabidopsis. PLoS One 15:e0222480. doi: 10.1371 /journal.pone.0222480

Conflict of Interest: The authors declare that the research was conducted in the absence of any commercial or financial relationships that could be construed as a potential conflict of interest.

Publisher's Note: All claims expressed in this article are solely those of the authors and do not necessarily represent those of their affiliated organizations, or those of the publisher, the editors and the reviewers. Any product that may be evaluated in this article, or claim that may be made by its manufacturer, is not guaranteed or endorsed by the publisher.

Copyright (c) 2021 Han, Kwak and Qi. This is an open-access article distributed under the terms of the Creative Commons Attribution License (CC BY). The use, distribution or reproduction in other forums is permitted, provided the original author(s) and the copyright owner(s) are credited and that the original publication in this journal is cited, in accordance with accepted academic practice. No use, distribution or reproduction is permitted which does not comply with these terms. 